\title{
LA SEXUALIDAD METABIOLOGICA: DE LA NATURALEZA AL LENGUAJE
}

\author{
José S. Lázaro
}

\section{Introducción}

«Se ha dicho que los príncipes asiáticos solían en ocasiones obligar a un número de señoras a correr por el jardín hasta sudar y cansarse, después de lo cual sus ropas eran llevadas al príncipe y éste elegía a una de las damas por el olor que de su túnica se desprendía» (1).

Vale la pena detenerse en el gesto del príncipe asiático que, en la soledad de su palacio, se inclina para olfatear detenida y voluptuosamente las ropas usadas por mujeres a las que no conoce, dejando que cada uno de los olores depositados en ellas levante en su interior resonancias que apenas podemos imaginar, hasta que, después de un largo y sin duda placentero examen, el olor de una de aquellas túnicas le lleve a realizar la elección sexual.

La historia recogida por Havellock Ellis es importante, al margen de que alguna vez haya ocurrido o no en algún remoto palacio de Asia. Si efectivamente ocurrió, su importancia derivaría del carácter de 
muestra significativa del comportamiento sexual humano. Pero si no hubiese ocurrido nunca, su importancia procedería del carácter de fantasía sexual, profundamente reveladora del deseo subyacente en la imaginación de su desconocido inventor.

En cualquier caso, el gesto del príncipe nos sitúa ante un enigma esencial: el enigma de la naturaleza, de la estructura, del sentido profundo de la sexualidad humana. Un enigma que cabe abordar desde dos puntos de vista opuestos.

El primero entiende la sexualidad como un fenómeno esencialmente biológico: será representado aquí por la que denominaremos concepción ilustrada de la sexualidad. El segundo la interpreta como algo irreductible a las leyes naturales de la biología, como un fenómeno metabiológico. Su representante aquí será la que llamaremos concepción lingüistica de la sexualidad.

La tesis que se propone a discusión es que el paso de un punto de vista a otro supone un auténtico cambio de paradigma y uno de los acontecimientos más importantes de la historia de la teoría sexual.

\section{La sexualidad biológica}

La ideología ilustrada sobre la sexualidad es fácil de resumir. La sexualidad es un instinto natural y la Naturaleza es la que establece las pautas del comportamiento virtuoso. El hombre será feliz si es virtuoso y será virtuoso si obedece a sus impulsos naturales. El impulso es la puesta en acto del deseo y el deseo es la voz mediante la cual la Naturaleza comunica a sus criaturas lo que deben de hacer. Esto es lo que nos enseña la razón, que es el único instrumento que permite comprender y acatar las leyes naturales. Todo código moral que se oponga a los instintos, a los deseos y a los impulsos naturales ha de ser rechazado por erróneo y dañino. Diderot lo expresó, en la Encyclopédie, con una frase rotunda: "Se entiende por moral lo que en un hombre de bien equivale a lo natural» (2).

Podrían acumularse los ejemplos de este tipo de razonamiento que marcó profundamente el Siglo de las Luces. El Barón D'Holbach, buen representante del materialismo más radical de la época, escribe en su Sistema de la Naturaleza:

«Prohibir las pasiones a los hombres es prohibirles ser hombres; aconsejar a una persona de imaginación exaltada que modere sus deseos es aconsejarle que cambie su organización, es ordenar a su san- 
gre que corra más despacio. Decir a un hombre que renuncie a sus hábitos es querer que un ciudadano acostumbrado a ir vestido consienta en andar desnudo; sería lo mismo decirle que cambie los rasgos de su cara, destruya su temperamento, apague su imaginación, altere la Naturaleza de sus fluidos, que ordenarle que no tenga pasiones análogas a su energía natural, o que renuncie a las que el hábito y sus circunstancias le han hecho contraer y han convertido en necesidades» (3).

Los deseos y las pasiones serían, por tanto, fuerzas heterónomas al individuo. La voluntad personal no tendría ningún control sobre ellas. El sujeto estaría (según esta concepción del materialismo ilustrado) sometido y determinado por un orden natural que le trasciende. Esas fuerzas determinantes son consideradas por Holbach como una «energía natural» que constituiría la esencia misma del hombre.

Diderot, en un coloquio escrito en 1769 , le hará decir al Doctor Bordeu:

"Todo lo que es no puede ser ni contra natura ni fuera de la naturaleza, y no exceptúo ni siquiera la castidad y la continencia voluntarias, que serían los primeros crímenes contra naturaleza, si se pudiese pecar contra naturaleza, y los primeros crímenes contras las leyes sociales de un país en el que se pesasen las acciones con otra balanza que la del fanatismo y el prejuicio» (4).

De esta manera Diderot hace que todo lo que pueda ser sea natural por definición. El término «antinatural» queda tan vacío de contenido que ni siquiera «la castidad y la continencia voluntarias» pueden ser consideradas antinaturales. Y, puesto que ya no puede condenarlas desde una moral naturalista, tiene que recurrir al artificio de imaginar las «leyes sociales» de un país utópicamente ilustrado para que ellas condenen cuanto se oponga a la voluptuosidad de la Naturaleza.

En el Suplemento al viaje de Bougainville, sátira demoledora del moralismo religioso, Diderot recreará el mito del buen salvaje, y hará que un anciano indígena de Tahití despida a los europeos que han pasado unos días en la isla (dejando la sífilis de recuerdo) con un discurso tan ilustrado como poco verosímil:

"Y tú, jefe de estos canallas que te obedecen, aleja presto tu nave de nuestra orilla: somos inocentes, somos felices; y tú no puedes malograr nuestra felicidad. Seguimos el puro instinto de la naturaleza y tú has intentado borrar de nuestras almas su carácter. Aquí todo 
es de todos y tú nos has predicado no sé qué distinción de lo tuyo y lo mío. Nuestras hijas y nuestras mujeres nos son comunes; has compartido este privilegio con nosotros y has venido a encender en ellas furores desconocidos. En tus brazos enloquecieron, tú te volviste feroz entre los suyos. Ellas empezaron a odiarse; vosotros os asesinasteis por ellas; y ellas han vuelto a nosostros teñidas con vuestra sangre» (5).

Los deseos naturales son, según esto, inocentes y quien los obedece y sigue «el puro instinto de la naturaleza» tiene garantizada la felicidad. Pero basta un contacto con los artificios de la civilización para que este paraíso natural sea invadido por "furores desconocidos», por afán de posesión, por locura, odio, sangre y muerte.

El hijo de las luces que llevó estos planteamientos hasta sus consecuencias más extremas fue el Marqués de Sade. Si el deseo es la voz de la Naturaleza y la Naturaleza es la gran legisladora, si todo deseo es, por definición, legítimo, y ninguno puede ser censurado, se deduce que el incesto, la crueldad, la tortura o el engaño, cuando son fruto del deseo y productores de placer sólo pueden ser vistos con simpatía. Si un libertino desea matar por placer, debe hacerlo, pues al fin y al cabo el asesinato no es más que una variación de las formas de la materia. Con razón ha señalado Fernando Savater que la audacia de Sade profundiza en «la cara oscura del Siglo de las Luces, esa vertiente que los philosophes rara vez quisieron afrontar» (6).

Las obras principales de Sade (7) tienen una estructura muy simple en la que se alternan dos tipos de escenas: la descripción minuciosa de una orgía es seguida por un discurso de teoría libertina, que da paso a una nueva bacanal que a su vez terminará en otro discurso y así sucesivamente durante cientos de páginas.

Pues bien, el discurso teórico de Sade repite una y otra vez, con mínimas variaciones, que la razón nos muestra el carácter natural de cualquer deseo, legitimando su realización. Pero su discurso narrativo nos muestra en cambio a cada paso que las caprichosas pulsiones sexuales del sujeto humano tienen muy poco que ver con los instintos biológicos de la especie y que tratar de reducirlas a estos sería tan inútil como tratar de encerrar las "pasiones libertinas» que Sade pinta en la función procreativa. Lo que sus narraciones evidencian no cabe, por razones culturales e históricas, en sus argumentaciones. Sus descripciones tratan continuamente de forzar los límites «razonables»y «naturales» que sus teorizaciones ilustradas intentan, en vano, imponerles. 
La teoría de Sade es compatible con una concepción biológica de la sexualidad, pero su narrativa sólo puede ser adecuadamente comprendida desde una perspectiva metabiológica.

Podemos imaginar la explicación que daría un ilustrado del acto del príncipe asiático que, tras olfatear las ropas usadas por varias desconocidas, elegía favorita. Sin duda nos diría que el acto del príncipe es natural, es decir, que obedece a leyes biológicas. Puesto que el olfato no es precisamente el rey de los sentidos humanos, pero sí tenía en el comportamiento animal papel de protagonista, quizá llegaría a decirnos que la selección del príncipe muestra que el animal que hay en él domina sobre su parte humana, que su acto es uno de esos que hoy llamamos regresivos. Puede que nos dijese algo más, desde luego lo diría mucho mejor. Pero su explicación no llegaría a satisfacernos, no lograría hacer justicia a la capacidad de sugerencia de la imagen que Havellock Ellis nos dio. El gesto del príncipe asiático no puede ser suficientemente explicado desde la perspectiva biológica. Hay que tratar de entenderlo desde una concepción metabiológica.

\section{La sexualidad metabiológica}

El tema del olfato es ideal para entrar en el campo de la sexualidad metabiológica. Al revisar esa obra maestra de la literatura erótica que es El Cantar de los Cantares, en la traducción inimitable de Fray Luis de León, se encuentran, en sus escasas páginas, más de veinte referencias voluptuosas al olor del amado y de la amada:
«Béseme con su boca a mí el mi amado.
Son más dulces que el vino tus amores:
tu nombre es suave olor bien derramado, y no hay olor, que iguale tus olores» (8).

En el encantador prefacio que Casanova puso a sus Memorias, el famosolibertino nos proporciona una auténtica declaración de principios:

«Me han gustado los manjares de sabor fuerte; el paté de macarrones hecho por un buen cocinero napolitano, la olla podrida de los españoles, el bacalao de Terranova, bien pegajoso, la caza de aroma embriagador y los quesos cuya perfección se pone de manifiesto cuando los pequeños seres que en ellos se forman empiezan a hacerse visi- 
bles. En cuanto a las mujeres, siempre me ha parecido dulce el olor de las que he amado" (9).

El pensador que va a fundamentar la teoría metabiológica de la sexualidad, Sigmund Freud, distinguió en su metapsicología la representación de palabra (Wortvorstellung), de origen acústico, y la representación de cosa (Sachvorstellung o Dingvorstellung), de origen visual (10). Descuidó otras representaciones de importancia, en ocasiones, no menor: las táctiles, las gustativas, las olfativas. Recuérdense las consecuencias de la representación del sabor de una magadalena que despertó, en el aparato psíquico de Marcel Proust, esa larga cadena de asociaciones que conocemos por el nombre de En busca del tiempo perdido.

Si una representación puede tener tan vastas consecuencias, es a través del mecanismo de la evocación, de la reminiscencia. Breuer y Freud aseguran, en los Estudios sobre la histeria, que el trauma psíquico se enquista en lo más profundo de la mente y actúa como un cuerpo extraño capaz de producir síntomas. Esta hipótesis les permite afirmar que el histérico sufre por reminiscencias (11). Casanova se adelanta a sus futuros censores advirtiendo: "no se podría reprochar a mi ánimo gastado el que no sepa ya gozar sino por reminiscencia» (12). El histérico, a partir de un recuerdo (o más bien de un olvido) patógeno, sufriría pasivamente una serie de procesos psíquicos que consisten, según la teoría analítica, en la represión de ciertas representaciones y la elaboración o derivación de los afectos que las cargaban de significación. En otros términos: la psicogénesis de la histeria dependería de un juego de representaciones y afectos, es decir, de significantes y significados; de ahí su carácter lingüístico. Es este proceso lingüístico el que hará que el histérico sufra de reminiscencias. Por otro lado, el anciano libertino, hundiéndose en su memoria, se entregará a la recreación lingüística de los deseos y los placeres idos, y eso le permitirá gozar por reminiscencia.

Lo que nos va a enseñar la teoría freudiana de la sexualidad metabiológica es la profunda relación que existe entre el deseo y esa forma del lenguaje que es la reminiscencia.

Lo más parecido a una definición del deseo que nos ofrece Freud, se encuentra en el capítulo séptimo de La interpretación de los sueños (13). De este texto se deduce que el deseo es un mecanismo complejo que tiene como punto de partida la acumulación somática de excitación que produce una desagradable sensación de incomodidad. Dicho de otra manera, el origen del deseo es una necesidad biológica, pero 
su mecanismo de elaboración va a convertirlo en algo esencialmente distinto. El sujeto buscará una salida para la incómoda excitación acumulada. En esa búsqueda se volverá hacia las representaciones (conservadas por su memoria más remota) de su primeras vivencias de satisfacción (es decir, de eliminación de una tensión displacentera) y hacia las representaciones, ligadas con éstas, del objeto que las hizo posibles, generalmente la madre. La madre aportó a su niño el alimento que necesitaba, y al mismo tiempo le aportó su presencia, el contacto de su piel cálida, su olor inconfundible, palabras cariñosas susurradas al oído... Cada una de esas percepciones quedará depositada en el interior del sujeto que se está humanizando, y quedará depositada en forma de representaciones (o, si se prefiere, de significantes): representaciones visuales, auditivas, táctiles, olfativas, gustativas. Representaciones que se irán acumulando en forma de huellas mnémicas, asociadas entre sí formando redes complejas y asociadas además a la huella de la excitación displacentera. Las relaciones de asociación serán las mismas que emplean para asociarse los signos del lenguaje: relaciones de analogía y relaciones de contigüidad.

Cuando la excitación resurja y el aparato psíquico realice una profunda introspección en busca de las representaciones del objeto y del acto capaces de eliminar la excitación, las encontrará formando parte de una larga cadena que recorrerá sin poder evitarlo. Será alguna representación de esa cadena, probablemente muy alejada de la que se buscaba, la que acabará por manifestarse como objeto del deseo. Una de esas cadenas se plasmó en la obra famosa de Proust. Un recorrido por esas redes de representaciones es lo que realiza en el diván el paciente realmente entregado a la asociación libre. Una cadena de una de esas redes fue lo que permitió al príncipe asiático, partiendo del olor de unas túnicas, relacionarlo con una representación depositada en algún lugar de su aparato psíquico y, a partir de ésta, realizar un largo monólogo interior que desembocará en la cristalización del deseo y permitirá elegir favorita. Decisión sin duda errónea, como cualquier otra, pues difícilmente podría un objeto real coincidir plenamente con los fantasmas del pasado despertados por la reminiscencia del príncipe.

La concepción del deseo como artificio lingüístico - que Lacan señaló sobre los textos de Freud y desarrolló ampliamente (14)- es uno de los argumentos que apoyan la afirmación de que no es posible reducir la teoría sexual freudiana a una concepción biológica. Freud adoptó el término metapsicología para referirse a sus elaboraciones teóricas que no cabían en las psicologías centradas en la conciencia. Análo- 
gamente puede emplearse el término metabiología para referirse a una teoría de la conducta que no cabe en los planteamientos naturalistas, a una teoría del sujeto humano como auténtico ser sobrenatural, metabiológico.

La teoría freudiana del deseo nos daba un buen ejemplo de planteamiento irreductible a la biología. Encontraremos otro ejemplo en la clara conciencia que Freud tenía de la diferencia y el conflicto entre los intereses del individuo y los de la especie. Tanto en su artículo sobre el narcisismo (15) como en las Conferencias de introducción al psicoanálisis (16) Freud señala que cada individuo es su propio fin, pero a la vez es un simple eslabón de la cadena biológica. La sexualidad es una función individual, pero a la vez trasciende al individuo y lo empuja a la realización de actos que no dependen por completo de su voluntad. Por esos actos pagará un precio (las molestias y los riesgos, a veces mortales, que suponen) y recibirá un premio: el placer. Ese premio que el individuo busca es bien distinto del beneficio que la especie logra: la posibilidad de un nuevo ejemplar de lo mismo, de un nuevo eslabón. Cada sujeto emplea los medios que la especie le da, los transmite a su descendencia y se extingue. Cada sujeto humano tiene uso de razón y voluntad propia (generalmente en menor medida de lo que cree) pero a la vez no es más que un instrumento desechable, al servicio de mecanismos que le trascienden.

Una importante cuestión terminológica permite profundizar en este tema. Freud emplea el término instinto (Instinkt) en muy pocas ocasiones a lo largo de sus obras, y prácticamente siempre que lo emplea es para referirse al comportamiento animal. El término habitual con el que se refiere al mecanismo determinante de la conducta humana es, como se sabe, pulsión (Trieb). El instinto es una fuerza elemental y unidireccional; mientras que la pulsión sexual está compuesta por una gran cantidad de pulsiones parciales que, orientadas a diferentes zonas erógenas, sólo logran integrarse en la pulsión genital de forma provisional e imperfecta. El instinto es homogéneo e indivisible, mientras que la pulsión es heterogénea, compuesta de diversos elementos que forman una estructura inestable, siempre amenazada por la posibilidad de la dispersión.

El instinto es el medio por el cual el orden biológico determina directamente el comportamiento animal; la pulsión es un concepto complejo que trata de explicar todo lo que media entre un estímulo y un acto humano. Y lo que media es todo el mecanismo que se ha descrito al hablar del deseo, concepto íntimamente relacionado con el de pul- 
sión, que viene a ser, en cierto modo, la puesta en acto del deseo. El estímulo original, que Freud concibe como una excitación ciega de origen somático, investirá una huella mnémica, por ejemplo, la de un olor percibido en la infancia más remota. Esa huella mnémica, recuperada de algún oscuro rincón del sótano de la mente, estará, como se vio, asociada con otras. Freud hablaba de cadenas de representaciones recorridas por afectos, por cargas de energía psíquica. Hoy se tiende a hablar de cadenas de significantes portadores de sentido. En cualquier caso, se desarrolla un proceso lingüístico del cual emerge una representación, un significante que señala el objeto de la pulsión, la elegida del príncipe asiático. Es este mecanismo el que hace de las pulsiones sexuales humanas algo difícilmente previsible, profundamente caprichoso y peculiar de cada persona y de cada momento, algo que busca un cierto objeto y lo busca con un cierto fin, pero que no permite que ninguna ley natural o moral decida previamente cuál es ese objeto y cuál es ese fin. La sexualidad humana no se somete a las leyes de la biología, más bien parece estar relacionada con los juegos de palabras. Parafraseando una célebre tesis de Lacan, se podría decir que la sexualidad humana está estructurada como un lenguaje.

Freud rompe definitivamente con las teorías biológicas de la sexualidad y las sustituye por una concepción metabiológica, igual que había roto con la psicología decimonónica de la conciencia para sustituirla por su metapsicología. Y sus textos dan la impresión de que lo hace sin darse cuenta del alcance de lo que está haciendo. Freud nunca afirma explícitamente que su idea de la sexualidad se sitúe más allá de los límites de la biología. $\mathrm{O}$, mejor dicho, lo afirma y lo niega. La primera edición de sus Tres ensayos de teoría sexual (1905) termina con una justificación:

«El resultado insatisfactorio de estas investigaciones sobre los trastornos de la vida sexual es debido a que no sabemos bastante sobre los procesos biológicos que sostienen la esencia de la sexualidad» (17).

Y, sin embargo, en el prólogo escrito diez años más tarde para la tercera edición del mismo libro, se afirma:

«Junto a su fundamental dependencia de la investigación psicoanalítica, debo destacar, como característica de este trabajo mío, su deliberada independencia de la investigación biológica» (18). 
Contrastes como éste indican que hay que optar por una de las lecturas posibles de Freud. La que aquí se propone es una lectura fechada a finales de un siglo durante el cual muchos de sus mejores pensadores han dedicado muchas de sus mejores páginas a reflexionar sobre el lenguaje. Una lectura deudora de la peculiar interpretación de Freud realizada por Lacan, aunque no por eso ha de sentirse obligada a encerrarse en los límites de su teoría. Una lectura discutible y defendible, como otras, pero probablemente más fructífera y emancipadora que otras por las perspectivas que abre al señalar que el mito naturalista de la biología tiene muy poco valor a la hora de explicar las raíces de la conducta humana y muy poco derecho a servir de apoyo a imperativos morales.

\section{NOTAS}

(1) ElLis; H. (1897-1910): Estudios de psicología sexual, V, «La selección sexual en el hombre", Madrid, Reus, 1913, p. 67.

(2) Diderot, citado en: HAZARD, P. (1946): El pensamiento europeo en el siglo XVIII, Madrid, Alianza, 1985, p. 147. Además del excelente libro de Hazard, pueden verse sobre este; tema: CASSIRER, E. (1932): Filosofía de la Ilustración, México, Fondo de Cultura Económica, 3. ${ }^{a}$ ed., $1 .^{\mathrm{a}}$ reimp., 1975, pp. 54-112; EHRARD, J. (1970): L'idée de Nature en France à l'aube des lumières, París, Flammarion; GAY, P. (1970): The Enlightenment: an Interpretation, II: The Science of Freedom, London, Wildwood House, reimp. 1979, pp. 187-207.

(3) HolbaCh, P. H. D (1770): Sistema de la Naturaleza, Madrid, Editora Nacional, 1982, p. 331

(4) Diderot, D. (1830): Coloquio entre D'Alambert y Diderot. En: Escritos Filosóficos, Madrid, Editora Nacional, 1975, p. 108.

(5) Diderot, D. (1796): Suplemento al viaje de Bougainville. En: Bougainville, L. A de: Viaje a Tahití, Barcelona, José J. de Olañeta, 1982, p. 109-110.

(6) SAVATER, F. (1978): «La Ilustración». En: A.A.V.V.: Historia de la Filosofía, Madrid Noguer, p. 290

(7) Por las obras principales hay que entender La nouvelle Justine ou les malheurs de la vertu. Suivie de l'histoire de Juliette, sa soeur, ou les prospérités du vice [SADE (1797). En: Oeuvres complètes, VI-IX, París, Cercle du Livre Précieux, 1966-67], y ese compendio de la obra sadiana que se titula La philosophie dans le boudoir [SADE (1795). En: Oeuvres complétes, III, ed. cit.]. Queda al margen Les cent vingt journées de Sodome [SADE (1904). En: Oeuvres complétes, XIHI, ed. cit.], por las peculiaridades estructurales de ese extremoso catálogo de las llamadas, por la medicina, "perversiones sexuales», y que su autor prefiere denominar "pasiones libertinas".

(8) «Los Cantares de Salomón en octava rima». En: Fray Luis de León: Poesias, Madrid, Cupsa, 3. ${ }^{\mathrm{a}}$ ed., 1977, p. 153.

(9) Casanova, G. (1822): Memorias, I, Madrid, Aguilar, 1982, p. 34.

(10) FreUd, S. (1915): «Das Unbewusste». En: Studienausgabe, III, Frankfurt am Main, S. Fisher, 1969-79, pp. 159-61. 
(11) Breuer, J. y Freud, S. (1893-95): Estudios sobre la histeria. En: Freud, S.: Obras completas, II, Buenos Aires, Amorrortu, pp. 29-33. (Texto no incluido en ŚStudienausgabe).

(12) Casanova (1822): p. 37.

(13) Freud, S. (1900): Die Traumdeutung. En: Studienausgabe, II, ed. cit., pp. 538:39.

(14) LACAN, J. (1960): «El deseo y su interpretación». En: Las formaciones. del incons. ciente, Buenos Aires, Nueva Visión, 1970, pp. 125-73; LaCAN, J. (1966): Ecrits, París, Seuil.

(15) Freud, S. (1914): «Zur Einführung des Narzisismus». En: Studienausgabe, III, ed. cit., pp. 45-46.

(16) FREUD, S. (1916-17): Vorlesungen zur Einführung in die Psychoanalyse. En: Studienausgabe, I, ed. cit., pp. 399-40.

(17) Freud, S. (1905): Drei Abhandlungen zur Sexualtheorie. En: Studienausgabe, V, ed. cit., p. 145 .

(18) Freud, S. (1915): «Vorwort zur dritten Auflage». En: Freud (1905), p. 44. 